\title{
Risk of Cardiovascular Disease among Diabetic Patients in Manipur, Northeast India
}

\author{
Mary Grace Tungdim, ${ }^{1}$ T. Ginzaniang, ${ }^{2}$ G. Poufullung Kabui, ${ }^{2}$ \\ Deepali Verma, ${ }^{1}$ and Satwanti Kapoor ${ }^{1}$ \\ ${ }^{1}$ Department of Anthropology, University of Delhi, Delhi 110007, India \\ ${ }^{2}$ Department of Medicine, Jawaharlal Nehru Institute of Medical Sciences (JNIMS), Imphal, Manipur 795001, India \\ Correspondence should be addressed to Mary Grace Tungdim; marygracezou@yahoo.co.in
}

Received 21 February 2014; Revised 22 April 2014; Accepted 30 April 2014; Published 26 May 2014

Academic Editor: Kaushik Bose

Copyright (C) 2014 Mary Grace Tungdim et al. This is an open access article distributed under the Creative Commons Attribution License, which permits unrestricted use, distribution, and reproduction in any medium, provided the original work is properly cited.

\begin{abstract}
Atherosclerotic cardiovascular disease is the major cause of premature mortality in patients with type 2 diabetes. The present study was conducted to assess cardiovascular risk among diabetic patients of Northeast India. The present cross-sectional study included 81 diabetic patients (39 males and 42 females) aged 36-74 years from the district Imphal of Manipur, Northeast India. Sex-specific Framingham general cardiovascular risk prediction equations were used to calculate the 10-year risk for cardiovascular disease. The probable risk factors were determined by cross-tabulation of cardiometabolic parameters with the 10-year cardiovascular risk level. Males were found to be at higher risk of developing CVD in the future as compared to females with a discernible accumulation of adverse cardiovascular risk factors among them. 38.3\% patients were at high risk, $37.0 \%$ at moderate risk and $24.7 \%$ at low risk for developing CVD in the next 10 years. Systolic blood pressure, total cholesterol, triglyceride, and smoking contributed significantly to high degree of cardiovascular risk. Presence of cardiovascular risk factors among diabetic patients at diagnosis accentuates the need of intensive management of cardiovascular complications, taking into consideration the traditional dietary pattern of the population.
\end{abstract}

\section{Introduction}

Changes in the human environment, behaviour, and lifestyle are contributing to the upsurge in the incidence of diabetes. However, better management has resulted in a longer survival of patients with diabetes, but it is accompanied by long-term chronic complications due to hyperglycemia [1]. Individuals with diabetes most often die of cardiovascular disease (CVD) rather than from a cause uniquely related to diabetes, such as ketoacidosis or hypoglycemia [2]. Diabetic patients have a twofold to sixfold higher incidence of cardiovascular disease than nondiabetic population [3]. Furthermore, diabetic patients with CVD sustain a worse prognosis for survival than CVD patients without diabetes and their quality of life also depreciates. Therefore, diabetes has been considered as having a risk equivalent to a nondiabetic patient with preexisting heart disease [4]. Identification of patients at risk for CVD could felicitate the prevention or retardation of cardiovascular events.

Lifetime risk estimates provide a simple conceptual basis for estimating the absolute risk of developing disease over the remaining lifespan [5]. Presence of several risk factors among diabetic patients suffering from cardiovascular disease stresses on the assessment of the individual's total burden of risk rather than on the level of any particular risk factor [6]. Several multivariate risk prediction algorithms [7-9] have been developed to predict future CVD risk but their use has lagged in primary care [10]. Sex-specific Framingham risk prediction model however has been incorporated in the report on Detection, Evaluation, and Treatment of High Blood Cholesterol in Adults, Adult Treatment Panel III (NCEP ATP-III) [11]. 


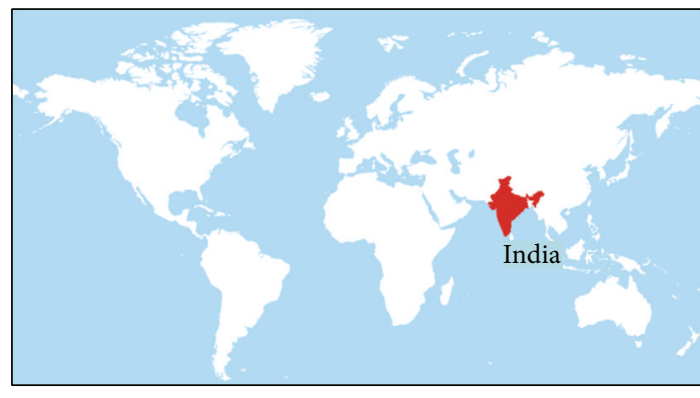

FIGURE 1: Location of India on world map.

In India (see Figure 1), regional variation has been reported in cardiovascular disease incidence and mortality. However, there lies a significant gap in the knowledge of CVD epidemiology and associated risk factors among Indian population especially among the Northeast population. The increasing prevalence of cardiovascular disease and diabetes emphasizes the need to bridge the gap by considering the distinct sociocultural, biological, and ethnic diversity of the Indian population. The purpose of our study was to assess the cardiovascular risk among type 2 diabetic patients of Manipur, Northeast India, based on Framingham prediction equations and to identify the associated risk factors. To our knowledge, no such studies have been conducted among the diabetic patients of Manipur.

\section{Methods}

2.1. Area and People. Manipur is one of the seven states of Northeast India (see Figure 2). The state is bound by Nagaland in the north, Mizoram in the south, Assam in the west, and the borders of the country Burma in the east as well as in the south. The state capital of Manipur is Imphal. The state lies at a latitude of $23^{\circ} 83^{\prime} \mathrm{N}-25^{\circ} 68^{\prime} \mathrm{N}$ and a longitude of $93^{\circ} 03^{\prime} \mathrm{E}-$ $94^{\circ} 78^{\prime} \mathrm{E}$. The total area covered by the state is $22,347 \mathrm{~km}^{2}$. The capital lies in an oval-shaped valley of approximately 700 square miles $(2,000 \mathrm{sq} \cdot \mathrm{km})$ surrounded by blue mountains and it is at an elevation of 790 metres above the sea level.

According to the census 2011 [12], Manipur has a population of approximately 2,570,390 people. The people of Manipur include the Meitei, Pangal (Muslims), Naga, and Kuki, who speak different languages of the Tibeto-Burman family. Despite their own distinct social and linguistic identity, they form a homogenous group by sharing biological and genetically similar characteristics, as the population ethnically belongs to Mongoloid stock. The rice is the staple food of the people who are nonvegetarian. They are mainly agriculturist. Some of them are involved in their own business and have also adopted jobs in private and governmental sectors to supplement their income.

2.2. Study Design. The present cross-sectional study included 81 diabetic patients (39 males and 42 females) aged 36-74 years who were outpatients of Jawaharlal Nehru Institute of Medical Sciences (JNIMS), Imphal, Manipur, Northeast India. The subjects were patients diagnosed as suffering

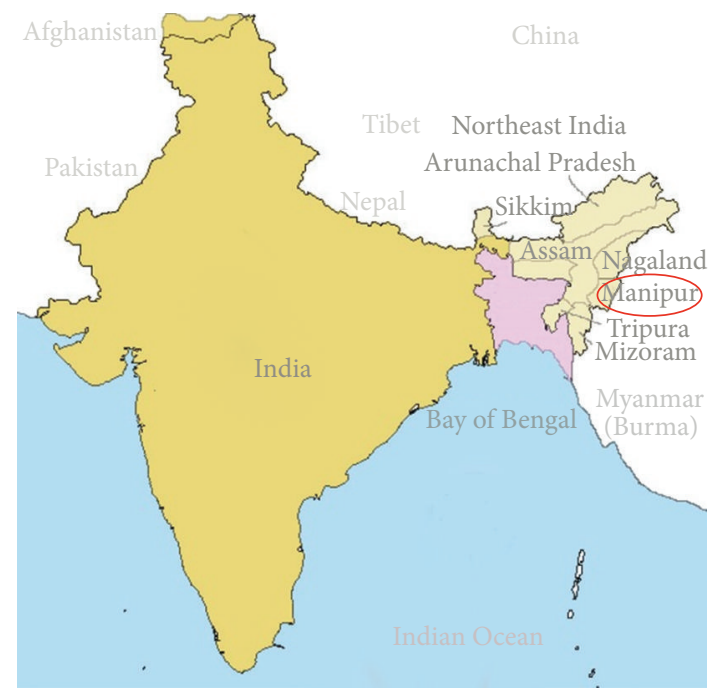

FIGURE 2: Location of Northeast region of India.

from diabetes by the doctors and whose fasting glucose (FG) level was $\geq 126 \mathrm{mg} / \mathrm{dL}$ [13]. Patients suffering from any cardiovascular disease were excluded from the study. The purpose of the study was explained to all the subjects prior to data collection. Informed written consent was obtained from each subject who volunteered for the study. The study protocol was approved by the Ethical Committee of the Department of Anthropology, University of Delhi, India.

The anthropometric measurements were taken using standard techniques of Weiner and Lourie [14]. Standing height was measured to the nearest 0.1 centimetre with fixed stadiometer. Body weight was measured in kilograms with a weighing scale to the nearest 0.5 kilogram. Waist and hip circumferences were recorded to the nearest $0.1 \mathrm{~cm}$ using a flexible steel tape. Body mass index (BMI) was derived by dividing the body weight by the height squared $\left(\mathrm{kg} / \mathrm{m}^{2}\right)$. Waist hip ratio (WHR) and waist height ratio (WHtR) were calculated. The patients were classified on the basis of body mass index (BMI) using WHO classification [15]. Central obesity was assessed by using WC (waist circumference), WHR, and WHtR standard criteria [16, 17].

Blood pressure, systolic (SBP) as well as diastolic (DBP), was recorded using an aneroid sphygmomanometer and stethoscope as recommended by the American Heart Association [18]. Patients were stratified into hypertensive and prehypertensive based on the definition of the Seventh Report, Joint National Committee on Prevention, Detection, Evaluation, and Treatment of High Blood Pressure [19].

The patients were referred to a laboratory where intravenous blood was drawn by trained technician after a fasting period of at least 8 hours to estimate the value of fasting glucose (FG), total cholesterol (TC), triglyceride (TG), high density lipoprotein (HDL), and low density lipoprotein (LDL). After analysing the blood, biochemical profile information (report) of the patients was given to the doctor for perusal. From the measurements of TC and HDL, the TC/HDL ratio was calculated. Dyslipidemia was defined by the presence of 
more than one abnormal serum lipid concentration. Subjects were classified into risk categories for each lipoprotein and TC/HDL ratio based on the National Cholesterol Education Program, Adult Treatment Panel III guidelines [11]. The uncontrolled glycemia was defined as having fasting blood glucose level $>140 \mathrm{mg} / \mathrm{dL}$ [20].

The 10-year risk of cardiovascular disease (CVD) was assessed by sex-specific general risk prediction equations derived by D'Agostino Sr. et al. [21] from Framingham Heart Study. Since in the original study the upper age limit of the cohort was 74 years, subjects aged 75 years and above were excluded in the present study to avoid erroneous risk score estimation. The different variables included in the scoring were age, systolic blood pressure, treatment for hypertension, smoking status, diabetes status, total cholesterol, and HDL (see Table 4). Tobacco intake and smoking status of the subjects were obtained using self-administered questionnaire. Based on the total risk score calculated, subjects were categorized to be at high $(>20 \%)$, moderate $(10-20 \%)$, and low $(<10 \%)$ risk of cardiovascular disease [11].

2.3. Statistical Analysis. Analysis was performed using SPSS version 17.0 (SPSS Inc., Chicago, IL, USA) software package. The distribution of data was explored using histogram with normality curve, and it was found to be normal. The basic characteristics were presented by descriptive analysis as means and standard deviations (SD) for continuous data and as frequencies for categorical data. An independent $t$-test was used to show the gender differences in the mean values of variables. A test of significance, that is, chi-square, was performed for comparison of distribution of risk factors in males and females and according to the 10-year risk level for developing CVD. Two-tailed probability $(P)$ value less than 0.05 was considered significant.

\section{Results}

Table 1 describes the baseline data of the diabetic patients. Mean age, onset age, and duration for diabetes were $55.4 \pm$ 9.27 years, $50.0 \pm 9.41$ years, and $5.5 \pm 5.01$ years, respectively, with no gender differences. Males were significantly taller $(166.8 \pm 7.60 \mathrm{~cm})$ and heavier $(61.7 \pm 9.24 \mathrm{~kg})$ than females (height $-151.9 \pm 8.41 \mathrm{~cm}$, weight $-56.8 \pm 10.37 \mathrm{~kg}$ ) but the latter had higher BMI $\left(24.7 \pm 4.78 \mathrm{~kg} / \mathrm{m}^{2}\right)$ as compared to males $\left(22.1 \pm 2.85 \mathrm{~kg} / \mathrm{m}^{2}\right)$. Mean values for central adiposity (WC and WHtR) were also significantly higher among females than males, while the cardiometabolic risk factors, SBP (134.7 $\pm 16.70 \mathrm{mmHg})$, fasting glucose $(190.3 \pm 89.00 \mathrm{mg} / \mathrm{dL})$, and estimated 10-year cardiovascular risk score $(28.5 \pm 17.22)$, were significantly higher among males than females (126.3 \pm $13.45,146.7 \pm 84.68$, and $13.9 \pm 8.68$ resp.).

The sex-wise distribution of patients in different categories of cardiovascular risk factors has been presented in Table 2. The analysis reveals that overall $28.4 \%$ were overweight, out of which a major proportion was of females (38.1\%) as compared to males $(17.9 \%)$ but the difference was not statistically significant. Central obesity was also more frequent among females (WC-84.6\%, WHtR-84.4\%) than males (WC-15.4\%, WHtR-47.2\%). Considering both SBP and DBP, $61.7 \%$ of the patients were hypertensive and $33.3 \%$ were prehypertensive. Significant gender differential was observed for SBP when considered individually, with $56.4 \%$ hypertensive males in comparison to $16.7 \%$ hypertensive females and $28.2 \%$ prehypertensive males than $61.9 \%$ prehypertensive females. The most common risk factors were high triglyceride (61.7\%) followed by high HDL (35.8\%). $24.7 \%$ of diabetic patients were dyslipidemic. According to the TC/HDL ratio, only $3.7 \%$ of patients were at the risk of cardiovascular diseases. However, no gender differences were found for the risk category of lipid profile. $37.0 \%$ of individuals either smoke or consume tobacco and $48.0 \%$ have a family history of diabetes. Females have better glycaemia control $(55.6 \%)$ than males $(24.5 \%)$. The overall estimated risk score for the present population was $21.0(5.74 \pm 15.26)$ as shown in Table 1 . High risk was found in $38.3 \%$ patients, moderate in $37.0 \%$ patients, and low in $24.7 \%$ patients (Table 2). Cardiovascular risk showed significant sexual dimorphism with higher proportion of males at high risk (59.0\%) than females $(19.0 \%)$ while $45.2 \%$ of females were at moderate risk as compared to $28.2 \%$ of males.

Table 3 presents the distribution of risk factors for cardiovascular disease, according to the 10-year cardiovascular risk level, that is, low, moderate, and high. 29\% overweight patients were at high risk and $20 \%$ were at moderate risk for CVD in the next 10 years. The proportion however did not differ significantly from overweight patients (40\%) who are at low risk. Despite the high frequency of centrally obese patients, its association with cardiovascular risk level is nonsignificant. Among the patients who had high probability for the incidence of CVD in the future 10 years, $74.2 \%$ were hypertensive and $22.6 \%$ were prehypertensive while for those with moderate probability, $63.3 \%$ were hypertensive and $33.3 \%$ were prehypertensive. The distribution differed significantly for SBP when it was considered separately from DBP. Major proportion of diabetic patients in the risk category of total cholesterol (45.2\%) and triglyceride (71.0\%) were at high risk as compared to moderate risk $(23.35 \%$ and $70.0 \%$, resp.). Smoking was also found to be a significant predictor of cardiovascular risk among these patients with $67.7 \%$ at high risk than $32.3 \%$ who do not smoke or chew tobacco. On the other hand, $83.3 \%$ of patients who smoke or chew tobacco were at moderate risk in comparison to $16.7 \%$ who are nonsmokers or chew tobacco. Other risk factors taken into consideration however did not show any significant results.

\section{Discussion}

The present hospital-based study has reported the 10-year risk of developing CVD among type 2 diabetic patients and the probable risk factors. On the basis of the Framingham risk scores, approximately one-third of the subjects recruited for the study will have cardiovascular complications in the next 10 years. Males showed discernible frequency of adverse cardiovascular risk as compared to the females and had higher risk of developing CVD in the future. Similar findings have been reported by Gomes et al. [22] among Brazilian 
TABLE 1: Descriptive value for anthropometric and clinical characteristic of diabetic patients from Manipur, Northeast India.

\begin{tabular}{|c|c|c|c|c|c|}
\hline Variables & $\begin{array}{c}\text { Total }(N=81) \\
\text { Mean } \pm \text { SD }\end{array}$ & $\begin{array}{c}\text { Male }(N=39) \\
\text { Mean } \pm \text { SD }\end{array}$ & $\begin{array}{c}\text { Female }(N=42) \\
\text { Mean } \pm \text { SD }\end{array}$ & $t$-value & $P$ value \\
\hline Age (years) & $55.4 \pm 9.27$ & $55.6 \pm 8.69$ & $55.3 \pm 9.89$ & 0.135 & 0.893 \\
\hline Age of onset (years) & $50.0 \pm 9.41$ & $50.2 \pm 9.34$ & $49.8 \pm 9.63$ & 0.165 & 0.876 \\
\hline Duration (years) & $5.5 \pm 5.01$ & $5.4 \pm 4.86$ & $5.52 \pm 5.20$ & 0.124 & 0.670 \\
\hline Height $(\mathrm{cm})$ & $159.1 \pm 10.95$ & $166.8 \pm 7.60$ & $151.9 \pm 8.41$ & 8.358 & $<0.001$ \\
\hline Weight (kg) & $59.1 \pm 10.09$ & $61.7 \pm 9.24$ & $56.8 \pm 10.37$ & 2.240 & 0.028 \\
\hline Body mass index (BMI: $\mathrm{kg} / \mathrm{m}^{2}$ ) & $23.5 \pm 4.16$ & $22.1 \pm 2.85$ & $24.7 \pm 4.78$ & 2.989 & 0.004 \\
\hline Waist circumference (WC: $\mathrm{cm}$ ) & $85.9 \pm 9.01$ & $84.6 \pm 7.35$ & $87.26 \pm 10.25$ & 1.338 & 0.185 \\
\hline Waist hip ratio (WHR) & $0.95 \pm 0.06$ & $0.96 \pm 0.06$ & $0.94 \pm 0.05$ & 1.478 & 0.143 \\
\hline Waist height ratio (WHtR) & $0.53 \pm 0.70$ & $0.50 \pm 0.04$ & $0.57 \pm 0.07$ & 6.172 & $<0.001$ \\
\hline Systolic blood pressure (SBP: mmHg) & $130.3 \pm 15.59$ & $134.7 \pm 16.70$ & $126.3 \pm 13.45$ & 2.495 & 0.015 \\
\hline Diastolic blood pressure (DBP: $\mathrm{mmHg}$ ) & $85.0 \pm 10.81$ & $86.1 \pm 12.59$ & $84.0 \pm 8.89$ & 0.852 & 0.397 \\
\hline Cholesterol (mg/dL) & $184.0 \pm 42.48$ & $177.6 \pm 32.57$ & $189.9 \pm 49.63$ & 1.313 & 0.193 \\
\hline Triglyceride (mg/dL) & $177.1 \pm 60.50$ & $181.8 \pm 63.79$ & $174.9 \pm 57.70$ & 0.506 & 0.614 \\
\hline $\mathrm{LDL}(\mathrm{mg} / \mathrm{dL})$ & $48.8 \pm 14.77$ & $67.6 \pm 31.98$ & $87.4 \pm 42.40$ & 2.355 & 2.355 \\
\hline $\mathrm{HDL}(\mathrm{mg} / \mathrm{dL})$ & $77.8 \pm 38.81$ & $48.9 \pm 16.19$ & $48.7 \pm 13.51$ & 0.056 & 0.956 \\
\hline Fasting glucose level (mg/dL) & $167.7 \pm 88.98$ & $190.3 \pm 89.00$ & $146.7 \pm 84.68$ & 2.244 & 0.027 \\
\hline Framingham risk score (FRS) & $21.0 \pm 15.26$ & $28.5 \pm 17.22$ & $13.9 \pm 8.68$ & 4.845 & $<0.001$ \\
\hline
\end{tabular}

diabetic population which contradicts with the earlier studies reporting high cardiovascular mortality in women [23, 24]. Recent accumulating evidence has demonstrated that diabetes alters estrogen-related protective mechanism and causes pronounced adverse changes in cardiovascular risk factors leading to enhanced atherogenesis in females $[25,26]$. However, a recent meta-analysis showed that although the odds for CVD mortality were higher for women than for men with diabetes, the number of excess deaths attributable to diabetes was higher among men after adjusting for CVD risk factors [27].

The sex differentials in the cardiovascular risk among diabetic patients of Manipur, Northeast India, in present population could be attributed to better glycemic control among females as compared to males. Cross tabulation showed that $55.6 \%$ females have controlled glycaemia as compared to males $(24.5 \%)$ which contrasts with the risk for cardiovascular disease with major proportion of males (59.0\%) being at high risk as compared to females (19\%). Though the present study has not evaluated the direct effect of hyperglycemia on cardiovascular disease, previous literature which includes epidemiological and pathological studies have provided several contradicting findings concerned with detrimental effect of hyperglycemia on cardiovascular risk profile. High blood glucose level leads to oxidative stress and mitochondrial overproduction of superoxide which have been recognized in the pathogenesis of diabetic micro- and macrovascular complications [28]. Clinical trials investigating the efficacy of improving glycemic control have also reported a reduction in the risk of cardiovascular events [29-31]. However, some recent randomized trials have demonstrated contradicting finding with no significant improvement in cardiovascular risk as a consequence of intensive glucose lowering therapy [32-34].

The other probable explanation for such biological sex differences in cardiovascular morbidity risk could be the distinct biological as well as gender-related acculturation and lifestyle differences between males and females [35]. Lifestyle and cultural habits have demonstrated stronger influences on metabolic disorders than those from genetic factors [36]. In the present study, males were primarily involved in agriculture and supplement their livelihood by working in governmental and private sectors while majority of the females were homemakers. The gender difference in lifestyle depends on the sex-specific behaviour inculcated in an individual by family or society in which they live and it varies with age.

The elevated risk of cardiovascular events among diabetic versus nondiabetic patients emphasizes screening asymptomatic diabetic patients for CVD risk. It is based on the premise that earlier identification and stratification would lead to appropriate management of cardiovascular risk for both long term ( $>10$ years) and short term ( $\leq 10$ years). In the present study, $38.3 \%$ of patients were at high risk, $37.0 \%$ at moderate risk, and $24.7 \%$ at low risk for developing CVD in the next 10 years according to the Framingham risk score. Systolic blood pressure, total cholesterol, triglyceride, and smoking have contributed significantly to the high risk of developing CVD in the future among these patients, which are already distinguished as risk factors for CVD. Obesity (regional and central) despite being a prominent risk marker in this population has not significantly predicted the cardiovascular risk as assessed by Framingham risk score. This is in contrast to the earlier studies which have reported 
TABle 2: Sex-wise distribution of diabetic patients in different categories of the cardiovascular risk factors.

\begin{tabular}{|c|c|c|c|c|c|c|}
\hline Variables & Categories & Overall & Male & Female & Chi-square & $P$ value \\
\hline \multirow{3}{*}{ BMI } & Underweight & $7.4(6)$ & $7.7(3)$ & $7.1(3)$ & \multirow{3}{*}{4.109} & \multirow{3}{*}{0.128} \\
\hline & Overweight & $28.4(23)$ & $17.9(7)$ & $38.1(16)$ & & \\
\hline & Normal & $64.2(52)$ & $74.4(29)$ & $54.8(23)$ & & \\
\hline \multirow{2}{*}{ WC } & Risk & $45.7(37)$ & $15.4(6)$ & $84.6(33)$ & \multirow{2}{*}{27.819} & \multirow{2}{*}{$<0.001$} \\
\hline & Normal & $54.3(44)$ & $84.6(33)$ & $26.2(11)$ & & \\
\hline \multirow{2}{*}{ WHR } & Risk & $92.6(75)$ & $87.2(22)$ & $97.6(41)$ & \multirow{2}{*}{3.213} & \multirow{2}{*}{0.101} \\
\hline & Normal & $7.4(6)$ & $12.8(5)$ & $2.4(1)$ & & \\
\hline \multirow{2}{*}{ WHtR } & Risk & $64.3(63)$ & $47.2(25)$ & $84.4(38)$ & \multirow{2}{*}{14.728} & \multirow{2}{*}{$<0.001$} \\
\hline & Normal & $35.7(35)$ & $52.8(28)$ & $15.6(7)$ & & \\
\hline \multirow{3}{*}{ SBP } & Hypertensive & $35.8(29)$ & $56.4(22)$ & $16.7(7)$ & \multirow{3}{*}{14.348} & \multirow{3}{*}{0.001} \\
\hline & Prehypertensive & $45.7(37)$ & $28.2(11)$ & $61.9(26)$ & & \\
\hline & Normal & $18.5(15)$ & $15.4(6)$ & $21.4(9)$ & & \\
\hline \multirow{3}{*}{ DBP } & Hypertensive & $55.6(45)$ & $61.5(24)$ & $50.0(21)$ & \multirow{3}{*}{1.127} & \multirow{3}{*}{0.569} \\
\hline & Prehypertensive & $33.3(27)$ & $28.2(11)$ & $38.1(16)$ & & \\
\hline & Normal & $11.1(9)$ & $10.3(4)$ & $11.9(5)$ & & \\
\hline \multirow{2}{*}{ Cholesterol } & Risk & $28.4(23)$ & $30.8(12)$ & $26.2(11)$ & \multirow{2}{*}{0.209} & \multirow{2}{*}{0.806} \\
\hline & Normal & $71.6(58)$ & $69.2(27)$ & $73.8(31)$ & & \\
\hline \multirow{2}{*}{ Triglyceride } & Risk & $61.7(50)$ & $59.0(23)$ & $64.3(27)$ & \multirow{2}{*}{0.241} & \multirow{2}{*}{0.654} \\
\hline & Normal & $38.3(31)$ & $41.0(16)$ & $35.7(15)$ & & \\
\hline \multirow{2}{*}{ LDL } & Risk & $8.6(7)$ & $2.1(1)$ & $14.3(6)$ & \multirow{2}{*}{3.519} & \multirow{2}{*}{0.110} \\
\hline & Normal & $91.4(74)$ & $97.4(38)$ & $85.7(36)$ & & \\
\hline HDL & Risk & $35.8(29)$ & $41.0(16)$ & $31.0(13)$ & 0.893 & 0.365 \\
\hline & Normal & $64.2(52)$ & $59.0(23)$ & $69.0(29)$ & & \\
\hline TC/HDL ratio & Risk & $3.7(3)$ & $5.1(2)$ & $2.4(1)$ & 0.428 & 0513 \\
\hline 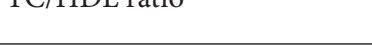 & Normal & $96.3(78)$ & $94.9(37)$ & $97.6(41)$ & & \\
\hline Dyslipidemic (2 risk factors) & Yes & $24.7(20)$ & $23.1(9)$ & $26.2(11)$ & 0.105 & 0.474 \\
\hline & No & $75.3(61)$ & $76.9(30)$ & $73.8(31)$ & & \\
\hline Smoke/tobacco & Yes & $37.0(30)$ & $43.6(17)$ & $31.0(13)$ & 1.385 & 0.239 \\
\hline & No & $63.0(51)$ & $56.4(22)$ & $69.0(29)$ & & \\
\hline Family history & Yes & $48.0(47)$ & $49.1(26)$ & $46.7(21)$ & 0.056 & 0.842 \\
\hline & No & $52.0(52.0)$ & $50.9(27)$ & $53.3(24)$ & & \\
\hline Glycemic control & Yes & $38.8(38)$ & $24.5(13)$ & $55.6(25)$ & 9.869 & 0.002 \\
\hline & No & $61.2(60)$ & $75.5(40)$ & $44.4(20)$ & & \\
\hline & Moderate & $37.0(30)$ & $28.2(11)$ & $45.2(19)$ & & \\
\hline 10-year cardiovascular risk & High & $38.3(31)$ & $59.0(23)$ & $19.0(8)$ & 14.300 & 0.001 \\
\hline & Low & $24.7(20)$ & $12.8(5)$ & 35.7 (15) & & \\
\hline
\end{tabular}

regional adiposity markers to be the predictor of cardiovascular risk [37-39]. This finding indicates the pioneer role of metabolic risk factors in the causation of disease among otherwise normal weight or obese patients. These identified risk factors have been reported as potential predictors among both diabetic and nondiabetic individuals [40]. However, at every level of risk factor, diabetic subjects have twofold higher risk [28], and the risk for disease increases over time with the accumulation of unfavourable metabolic factors [41].

Furthermore, in this study group, a large fraction of patients (61\%) had uncontrolled fasting blood glucose level which could be accredited to the rice intake, a staple diet of the population in the present study. Rice rich in carbohydrate has a high glycemic index (GI) which relates to the increased cardiovascular risk. The role of carbohydrates as a risk factor depends on their type; a high consumption of carbohydrates from high-GI foods rather than low-GI foods influences the risk of developing CVD [42]. The glycemic index value of white rice also depends on the degree of processing, cooking time, and amylose content but still is higher on average than that of whole grains [43]. These findings are in agreement with the other prospective study which has reported high dietary GI to be associated with increased CVD risk [44]. Another dietary component which plausibly explains the high cardiovascular risk in the present population is the frequent consumption of nonvegetarian food. Key et al. [45] have reported $28 \%$ reduced chance of developing heart disease among vegetarians than nonvegetarians due to lower 
TABLE 3: Cross tabulation of risk factors and 10-year cardiovascular risk level.

\begin{tabular}{|c|c|c|c|c|c|c|}
\hline \multirow{2}{*}{ Variables } & \multirow{2}{*}{ Categories } & \multicolumn{3}{|c|}{ 10-year cardiovascular risk level } & \multirow{2}{*}{ Chi-square } & \multirow{2}{*}{$P$ value } \\
\hline & & Low & Moderate & High & & \\
\hline \multirow{3}{*}{ BMI } & Underweight & $10.0(2)$ & $6.7(2)$ & $6.5(2)$ & \multirow{3}{*}{2.958} & \multirow{3}{*}{0.565} \\
\hline & Overweight & $40.0(8)$ & $20.0(6)$ & $29.0(9)$ & & \\
\hline & Normal & $50.0(10)$ & $73.3(22)$ & $64.5(20)$ & & \\
\hline \multirow{2}{*}{ WC } & Risk & $65.0(13)$ & $43.3(13)$ & $35.5(11)$ & \multirow{2}{*}{4.374} & \multirow{2}{*}{0.112} \\
\hline & Normal & $35.0(7)$ & $56.7(17)$ & $64.5(20)$ & & \\
\hline \multirow{2}{*}{ WHR } & Risk & $90.0(18)$ & $93.3(28)$ & $93.5(29)$ & \multirow{2}{*}{0.261} & \multirow{2}{*}{0.878} \\
\hline & Normal & $10.0(2)$ & $6.7(2)$ & $6.5(2)$ & & \\
\hline \multirow{2}{*}{ WHtR } & Risk & $75.0(15)$ & $57.8(26)$ & $66.7(22)$ & \multirow{2}{*}{1.912} & \multirow{2}{*}{0.385} \\
\hline & Normal & $25.0(5)$ & $42.2(19)$ & $33.3(11)$ & & \\
\hline \multirow{3}{*}{ SBP } & Prehypertensive & $50.0(10)$ & $53.3(16)$ & $35.5(11)$ & \multirow{3}{*}{21.261} & \multirow{3}{*}{$<0.001$} \\
\hline & Hypertensive & $5.0(1)$ & $33.3(10)$ & $58.1(18)$ & & \\
\hline & Normal & $45.0(9)$ & $13.3(4)$ & $6.5(4)$ & & \\
\hline \multirow{3}{*}{ DBP } & Prehypertensive & $45.0(9)$ & 36.7 (11) & $22.6(7)$ & \multirow{3}{*}{6.361} & \multirow{3}{*}{0.174} \\
\hline & Hypertensive & $35.0(7)$ & $56.7(17)$ & $67.7(21)$ & & \\
\hline & Normal & $20.0(4)$ & $6.7(2)$ & $9.7(3)$ & & \\
\hline \multirow{2}{*}{ Cholesterol } & Risk & $10.0(2)$ & $23.3(7)$ & $45.2(14)$ & \multirow{2}{*}{7.992} & \multirow{2}{*}{0.018} \\
\hline & Normal & $90.0(18)$ & $76.7(23)$ & $54.8(17)$ & & \\
\hline \multirow{2}{*}{ Triglyceride } & Risk & $40.0(8)$ & $70.0(21)$ & $71.0(21)$ & 6.011 & 0.050 \\
\hline & Normal & $60.0(12)$ & $30.0(9)$ & $29.0(9)$ & 0.011 & 0.050 \\
\hline LDL & Risk & $0.0(0)$ & $6.7(2)$ & $16.1(5)$ & 4.241 & 0.120 \\
\hline LDL & Normal & $100(20)$ & $93.3(28)$ & $83.9(26)$ & 4.241 & 0.120 \\
\hline HDI & Risk & $30.0(6)$ & $26.7(8)$ & $48.4(15)$ & 3.518 & 0.172 \\
\hline & Normal & $70.0(14)$ & $73.3(22)$ & $51.6(16)$ & 3.518 & $0.1 / 2$ \\
\hline $\mathrm{TC} / \mathrm{HDL}$ ratio & Risk & $0.0(0)$ & $3.3(1)$ & $6.5(2)$ & 1437 & 0.487 \\
\hline TC/HDL rato & Normal & $100(20)$ & $96.7(29)$ & $93.5(29)$ & $1.43 \%$ & $0.48 /$ \\
\hline Dyslinidemic & Yes & $15.0(3)$ & $20.0(6)$ & $35.5(11)$ & 3.31 & 0191 \\
\hline Dyslipidemic & No & $85.0(17)$ & $80.0(24)$ & $64.5(20)$ & 3.31 & 0.191 \\
\hline & Yes & $20.0(4)$ & $16.7(5)$ & $67.7(21)$ & & \\
\hline Smoke/tobacco & No & $80.0(16)$ & $83.3(25)$ & $32.3(10)$ & 20.361 & $<0.001$ \\
\hline Family history & Yes & $55.0(11)$ & 57.6 (19) & 37.8 (17) & 3.489 & 0.175 \\
\hline Family history & No & $45.0(9)$ & $42.4(14)$ & $62.2(28)$ & 3.489 & $0.1 / 5$ \\
\hline Glycemic control & Yes & $60.0(12)$ & $36.4(12)$ & $31.1(14)$ & 4.989 & 0.083 \\
\hline Glycemic control & No & $40.0(8)$ & $63.6(21)$ & $68.9(31)$ & 4.989 & 0.083 \\
\hline & $<5$ years & $27.9(20)$ & $30.2(13)$ & 41.9 (18) & & \\
\hline Duration & $5-10$ years & $17.5(7)$ & $37.5(15)$ & 45.0 (18) & 3.873 & 0.423 \\
\hline & $>10$ years & $6.7(1)$ & $33.3(5)$ & $60.0(9)$ & & \\
\hline
\end{tabular}

serum total cholesterol concentrations, when adjusted for the impact of BMI. This explanation supports the current finding where total serum cholesterol and triglyceride are found to be significantly associated with the cardiovascular risk. A study has found that restricted diet of diabetics has contributed significantly to the lower amount of zinc and magnesium in North-Eastern region of India [46]. Deficiency of these trace elements has been associated with increased incidence of cardiovascular disease and other diabetic complications [47, 48]. However, more studies probing such aspect of dietary components in relation to cardiometabolic diseases are needed.

\section{Limitation}

Considering the small sample size and cross-sectional study design, the authors could not generalize the findings of the present study to the entire population. However, probable reason based on the findings of the present study and the contrasting evidence put forth in the discussion from 
TABLE 4

\begin{tabular}{|c|c|c|}
\hline Variables & \multicolumn{2}{|c|}{ Classification criteria } \\
\hline \multirow{3}{*}{ BMI } & \multicolumn{2}{|c|}{ Underweight $<18.4 \mathrm{~kg} / \mathrm{m}^{2}$} \\
\hline & \multicolumn{2}{|c|}{ Normal $18.5 \mathrm{~kg} / \mathrm{m}^{2}-24.9 \mathrm{~kg} / \mathrm{m}^{2}$} \\
\hline & \multicolumn{2}{|c|}{ Overweight/obese $>25 \mathrm{~kg} / \mathrm{m}^{2}$} \\
\hline \multirow{8}{*}{ Blood pressure } & \multicolumn{2}{|l|}{ Systolic (SBP) } \\
\hline & \multicolumn{2}{|c|}{ Normal < $120 \mathrm{mmHg}$} \\
\hline & \multicolumn{2}{|c|}{ Prehypertensive $120-139 \mathrm{mmHg}$} \\
\hline & \multicolumn{2}{|c|}{ Hypertensive $>140 \mathrm{mmHg}$} \\
\hline & \multicolumn{2}{|c|}{ Diastolic (DBP) } \\
\hline & \multicolumn{2}{|c|}{ Normal $<80 \mathrm{mmHg}$} \\
\hline & \multicolumn{2}{|c|}{ Prehypertensive $80-89$} \\
\hline & \multicolumn{2}{|c|}{ Hypertensive $>90 \mathrm{mmHg}$} \\
\hline \multirow{2}{*}{ WC } & Male & Female \\
\hline & Risk $>94 \mathrm{~cm}$ & Risk $>80 \mathrm{~cm}$ \\
\hline \multirow{2}{*}{ WHR } & Male & Female \\
\hline & Risk $\geq 0.90 \mathrm{~cm}$ & Risk $\geq 0.85 \mathrm{~cm}$ \\
\hline \multirow{2}{*}{ WHtR } & \multicolumn{2}{|l|}{ Normal $<0.50$} \\
\hline & \multicolumn{2}{|l|}{ Risk $>0.50$} \\
\hline \multirow{2}{*}{ Cholesterol } & \multicolumn{2}{|c|}{ Normal $<200 \mathrm{mg} / \mathrm{dL}$} \\
\hline & \multicolumn{2}{|c|}{ Risk > $200 \mathrm{mg} / \mathrm{dL}$} \\
\hline \multirow{2}{*}{ Triglyceride } & \multicolumn{2}{|c|}{ Normal $<150 \mathrm{mg} / \mathrm{dL}$} \\
\hline & \multicolumn{2}{|c|}{ Risk > 150 mg/dL } \\
\hline \multirow{2}{*}{ LDL } & \multicolumn{2}{|c|}{ Normal $<130 \mathrm{mg} / \mathrm{dL}$} \\
\hline & \multicolumn{2}{|c|}{ Risk > 130 mg/dL } \\
\hline $\mathrm{HDL}$ & \multicolumn{2}{|c|}{ Risk $<40$ mg/dL } \\
\hline TC/HDL & \multicolumn{2}{|l|}{ Risk $>5.97$} \\
\hline Glycemic control & \multicolumn{2}{|c|}{ Uncontrolled > $140 \mathrm{mg} / \mathrm{dL}$} \\
\hline
\end{tabular}

the previous literature would provide an overview of the scenario. These findings need to be validated further through various epidemiological study designs, large sample sizes, and inclusion of various other sociodemographic and biological parameters.

\section{Conclusion}

Primary prevention through improved control of risk factors and therapeutic lifestyle modification (including dietary modification, aerobic exercise, and smoking cessation) is a pioneer strategy advocated by the National Cholesterol Education Program in the Adult Treatment Panel III (ATP III) guidelines [11]. Lifestyle interventions have been effective in the improvement of cardiovascular risk factors and the benefits are proportionally higher among those at high risk for cardiovascular disease [49]. However, the paradox in the prevention of cardiovascular complications of type 2 diabetes is that, at diagnosis, diabetic individuals are already at an amplified risk of CVD [50]. "Ticking clock" hypothesis postulates that the clock for coronary heart disease starts ticking before the onset of clinical diabetes [51]. It can also be attuned with the "common soil" hypothesis which postulates that both diabetes and CVD have common genetic and environmental antecedents. Furthermore, insulin resistance preceding long before the diagnosis of diabetes enhances atherogenic risk profile and has been delineated as a potential cause for subsequent increased risk of CVD among diabetic patients [52]. This mounting evidence accentuates the need of intensive management of cardiovascular risk factors among diabetic individuals. Therefore, there is a need of a comprehensive study design which includes various factors (biological, sociodemographic, and genetic) which directly or indirectly influence the disease incidence especially in a country with diverse ethnic population.

\section{Conflict of Interests}

The authors declare that there is no conflict of interests regarding the publication of this paper.

\section{Authors' Contribution}

The work presented here was carried out in collaboration between all authors. The study was conceptualized by author Mary Grace Tungdim. Authors T. Ginzaniang, G. Poufullung Kabui, and Mary Grace Tungdim contributed to the acquisition of data. Author Deepali Verma performed the statistical analysis and is responsible for interpretation of data. The paper was drafted by authors Mary Grace Tungdim and Deepali Verma. The paper was revised critically by Satwanti Kapoor, T. Ginzaniang, and G. Poufullung Kabui. All authors read and finally approved the paper for publication.

\section{Acknowledgments}

The authors are grateful to all the subjects for their participation and cooperation. The financial assistance to Mary Grace Tungdim by the Council of Scientific and Industrial Research (CSIR) and to Deepali Verma by University Grant Commission (UGC) is sincerely acknowledged.

\section{References}

[1] K. Gu, C. C. Cowie, and M. I. Harris, "Diabetes and decline in heart disease mortality in US adults," Journal of the American Medical Association, vol. 281, no. 14, pp. 1291-1297, 1999.

[2] N. J. Morrish, S.-L. Wang, L. K. Stevens et al., "Mortality and causes of death in the WHO multinational study of vascular disease in diabetes," Diabetologia, vol. 44, no. 2, pp. S14-S21, 2001.

[3] S. M. Haffner, S. Lehto, T. Rönnemaa, K. Pyörälä, and M. Laakso, "Mortality from coronary heart disease in subjects with type 2 diabetes and in nondiabetic subjects with and without prior myocardial infarction," The New England Journal of Medicine, vol. 339, no. 4, pp. 229-234, 1998.

[4] S. M. Grundy, I. J. Benjamin, G. L. Burke et al., "AHA scientific statement. Diabetes and cardiovascular disease. A statement for healthcare professionals from the American Heart Association," Circulation, vol. 100, no. 10, pp. 1134-1146, 1999.

[5] D. M. Lloyd-Jones, P. W. F. Wilson, M. G. Larson et al., "Framingham risk score and prediction of lifetime risk for coronary 
heart disease," American Journal of Cardiology, vol. 94, no. 1, pp. 20-24, 2004.

[6] S. M. Grundy, G. J. Balady, M. H. Criqui et al., "Primary prevention of coronary heart disease: guidance from Framingham: a statement for healthcare professionals from the AHA task force on risk reduction. American Heart Association," Circulation, vol. 97, no. 18, pp. 1876-1887, 1998.

[7] R. M. Conroy, K. Pyörälä, A. P. Fitzgerald et al., "Estimation of ten-year risk of fatal cardiovascular disease in Europe: the SCORE project," European Heart Journal, vol. 24, no. 11, pp. 9871003, 2003.

[8] P. M. Ridker, J. E. Buring, N. Rifai, and N. R. Cook, "Development and validation of improved algorithms for the assessment of global cardiovascular risk in women: the Reynolds Risk Score," Journal of the American Medical Association, vol. 297, no. 6, pp. 611-619, 2007.

[9] J. Hippisley-Cox, C. Coupland, Y. Vinogradova et al., "Predicting cardiovascular risk in England and Wales: prospective derivation and validation of QRISK2," British Medical Journal, vol. 336, no. 7659, pp. 1475-1482, 2008.

[10] A. Beswick and P. Brindle, "Risk scoring in the assessment of cardiovascular risk," Current Opinion in Lipidology, vol. 17, no. 4, pp. 375-386, 2006.

[11] "Third report of the national cholesterol education program (NCEP) expert panel on detection, evaluation, and treatment of high blood cholesterol in adults (adult treatment panel III) final report," Circulation, vol. 106, no. 25, pp. 3143-3421, 2002.

[12] “Census of India, Provisional population table," 2011, http://censusindia.gov.in/.

[13] American Diabetes Association, "Standards of medical care in diabetes," Diabetes Care, vol. 28, no. 1, pp. 5-36, 2005.

[14] J. S. Weiner and J. A. Lourie, Eds., Practical Human Biology, Academic Press, London, UK, 1981.

[15] World Health Organization, "Diet, nutrition and prevention of chronic disease. Report of a joint WHO/ FAO expert consultation," Tech. Rep. 916, 2003.

[16] World Health Organization, Waist Circumference and WaistHip Ratio: Report of a WHO Expert Consultation, Geneva, Switzerland, 2008.

[17] M. Ashwell, "Waist to height ratio and the Ashwell shape chart could predict the health risks of obesity in adults and children in all ethnic groups," Nutrition and Food Science, vol. 35, no. 5, pp. 359-364, 2005.

[18] T. G. Pickering, J. E. Hall, L. J. Appel et al., "Recommendations for blood pressure measurement in humans: an AHA scientific statement from the Council on High Blood Pressure Research Professional and Public Education Subcommittee," Journal of Clinical Hypertension, vol. 7, no. 2, pp. 102-109, 2005.

[19] A. V. Chobanian, G. L. Bakris, H. R. Black et al., "The seventh report of the joint national committee on prevention, detection, evaluation, and treatment of high blood pressure: the JNC 7 report," Journal of the American Medical Association, vol. 289, no. 19, pp. 2560-2572, 2003.

[20] American Diabetes Association, "Standards of medical care in diabetes," Diabetes Care, vol. 35, no. 1, pp. 11-63, 2012.

[21] R. B. D’Agostino Sr., R. S. Vasan, M. J. Pencina et al., "General cardiovascular risk profile for use in primary care: the Framingham heart study," Circulation, vol. 117, no. 6, pp. 743-753, 2008.

[22] M. B. Gomes, D. Giannella-Neto, M. Faria et al., "Estimating cardiovascular risk in patients with type 2 diabetes: a national multicenter study in Brazil," Diabetology and Metabolic Syndrome, vol. 1, no. 1, pp. 22-28, 2009.
[23] W. L. Lee, A. M. Cheung, D. Cape, and B. Zinman, "Impact of diabetes on coronary artery disease in women and men: a metaanalysis of prospective studies," Diabetes Care, vol. 23, no. 7, pp. 962-968, 2000.

[24] G. Hu, P. Jousilahti, Q. Qiao, S. Katoh, and J. Tuomilehto, "Sex differences in cardiovascular and total mortality among diabetic and non-diabetic individuals with or without history of myocardial infarction," Diabetologia, vol. 48, no. 5, pp. 856-861, 2005.

[25] H. O. Steinberg, G. Paradisi, J. Cronin et al., “Type II diabetes abrogates sex differences in endothelial function in premenopausal women," Circulation, vol. 101, no. 17, pp. 20402046, 2000.

[26] A. Juutilainen, S. Kortelainen, S. Lehto, T. Rönnemaa, K. Pyörälä, and M. Laakso, "Gender difference in the impact of type 2 diabetes on coronary heart disease risk," Diabetes Care, vol. 27, no. 12, pp. 2898-2904, 2004.

[27] A. M. Kanaya, D. Grady, and E. Barrett-Connor, "Explaining the sex difference in coronary heart disease mortality among patients with type 2 diabetes mellitus: a meta-analysis," Archives of Internal Medicine, vol. 162, no. 15, pp. 1737-1745, 2002.

[28] M. Laakso, "Cardiovascular disease in type 2 diabetes from population to man to mechanisms," Diabetes Care, vol. 33, no. 2, pp. 442-449, 2010.

[29] UK Prospective Diabetes Study (UKPDS) Group, "Intensive blood-glucose control with sulphonylureas or insulin compared with conventional treatment and risk of complications in patients with type 2 diabetes (UKPDS 33)," The Lancet, vol. 352, no. 9131, pp. 837-853, 1998.

[30] J. A. Dormandy, B. Charbonnel, D. J. A. Eckland et al., "Secondary prevention of macrovascular events in patients with type 2 diabetes in the PROactive study (PROspective pioglitAzone Clinical Trial in macroVascular Events): a randomised controlled trial," The Lancet, vol. 366, no. 9493, pp. 1279-1289, 2005.

[31] E. Mannucci, M. Monami, C. Lamanna, F. Gori, and N. Marchionni, "Prevention of cardiovascular disease through glycemic control in type 2 diabetes: a meta-analysis of randomized clinical trials," Nutrition, Metabolism and Cardiovascular Diseases, vol. 19, no. 9, pp. 604-612, 2009.

[32] The ADVANCE Collaborative Group, "Intensive blood glucose control and vascular outcomes in patients with type 2 Diabetes," The New England Journal of Medicine, vol. 358, pp. 2560-2572, 2008.

[33] The Action to Control Cardiovascular Risk (ACCORD) in Diabetes Study Group, "Effects of intensive glucose lowering in type 2 diabetes," The New England Journal of Medicine, vol. 358, no. 24, pp. 2545-2559, 2008.

[34] W. Duckworth, C. Abraira, T. Moritz et al., "Glucose control and vascular complications in veterans with type 2 diabetes," The New England Journal of Medicine, vol. 360, no. 2, pp. 129-139, 2009.

[35] A. Kiadaliri, P. M. Clarke, U. G. Gerdtham et al., "Predicting changes in cardiovascular risk factors in type 2 diabetes in the post-UKPDS era: longitudinal analysis of the Swedish National diabetes register," Journal of Diabetes Research, vol. 2013, Article ID 241347, 9 pages, 2013.

[36] J. F. Chiu, A. D. Bell, R. J. Herman et al., "Cardiovascular risk profiles and outcomes of Chinese living inside and outside China," European Journal of Cardiovascular Prevention and Rehabilitation, vol. 17, no. 6, pp. 668-675, 2010.

[37] M. Dhall, S. Gupta, M. Bhuker, P. Sharma, and S. Kapoor, "Effectiveness of various anthropometric indices in prediction of 
cardiovascular risk among adult jains," The Open Anthropology Journal, vol. 4, pp. 33-39, 2011.

[38] S. Czernichow, A.-P. Kengne, R. R. Huxley et al., "Comparison of waist-to-hip ratio and other obesity indices as predictors of cardiovascular disease risk in people with type-2 diabetes: a prospective cohort study from ADVANCE," European Journal of Cardiovascular Prevention and Rehabilitation, vol. 18, no. 2, pp. 312-319, 2011.

[39] P. Bhasin and S. Kapoor, "Pregnancy complications and calculated cardiovascular risk in urban women: do we envisage an association?" Journal of Urban Health, vol. 91, no. 1, pp. 162-175, 2014.

[40] J. Stamler, O. Vaccaro, J. D. Neaton, and D. Wentworth, "Diabetes, other risk factors, and 12-yr cardiovascular mortality for men screened in the multiple risk factor intervention trial," Diabetes Care, vol. 16, no. 2, pp. 434-444, 1993.

[41] S. C. Smith Jr., "Multiple risk factors for cardiovascular disease and diabetes mellitus," The American Journal of Medicine, vol. 120, no. 3, pp. S3-S11, 2007.

[42] S. Sieri, V. Krogh, F. Berrino et al., "Dietary glycemic load and index and risk of coronary heart disease in a large Italian cohort: the EPICOR study," Archives of Internal Medicine, vol. 170, no. 7, pp. 640-647, 2010.

[43] K. Foster-Powell, S. H. A. Holt, and J. C. Brand-Miller, "International table of gylcemic index and glycemic load values," American Journal of Clinical Nutrition, vol. 76, no. 1, pp. 5-56, 2002.

[44] E. B. Levitan, M. A. Mittleman, N. Håkansson, and A. Wolk, "Dietary glycemic index, dietary glycemic load, and cardiovascular disease in middle-aged and older Swedish men," American Journal of Clinical Nutrition, vol. 85, no. 6, pp. 1521-1526, 2007.

[45] T. J. Key, G. E. Fraser, M. Thorogood et al., "Mortality in vegetarians and nonvegetarians: detailed findings from a collaborative analysis of 5 prospective studies," American Journal of Clinical Nutrition, vol. 70, no. 3, pp. 516-524, 1999.

[46] R. Chakraborty, S. D. Dey, P. S. Dkhar, C. R. Thabah, and W. Rynjah, "Diabetics of Northeast India are at risk of dietary zinc and manganese deficiency: possible improvement through consumption of some traditional edibles or edibles of limited popularity," International Journal of Diabetes in Developing Countries, vol. 30, no. 4, pp. 201-207, 2010.

[47] G. Subramanium and T. Vijaya, Trace Elements in Cardiovascular Disease, Tirupati, India, SV Medical College, 1997.

[48] J. I. Anetor, A. Senjobi, O. A. Ajose, and E. O. Agbedana, "Decreased serum magnesium and zinc levels: atherogenic implications in type-2 diabetes mellitus in Nigerians," Nutrition and Health, vol. 16, no. 4, pp. 291-300, 2002.

[49] P. J. Watkins, "ABC of diabetes: cardiovascular disease, hypertension, and lipids," British Medical Journal, vol. 326, no. 7394, pp. 874-876, 2003.

[50] M. Laakso and S. Lehto, "Epidemiology of macrovascular disease in diabetes," Diabetes Reviews, vol. 5, pp. 294-315, 1997.

[51] S. M. Haffner, M. P. Stern, H. P. Hazuda, B. D. Mitchell, and J. K. Patterson, "Cardiovascular risk factors in confirmed prediabetic individuals. Does the clock for coronary heart disease start ticking before the onset of clinical diabetes?" Journal of the American Medical Association, vol. 263, no. 21, pp. 2893-2898, 1990.

[52] D. Eddy, L. Schlessinger, R. Kahn, B. Peskin, and R. Schiebinger, "Relationship of insulin resistance and related metabolic variables to coronary artery disease: a mathematical analysis," Diabetes Care, vol. 32, no. 2, pp. 361-366, 2009. 

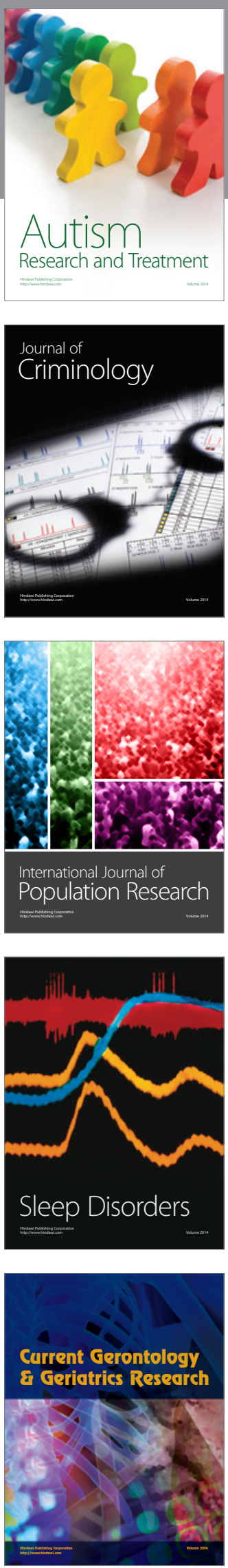
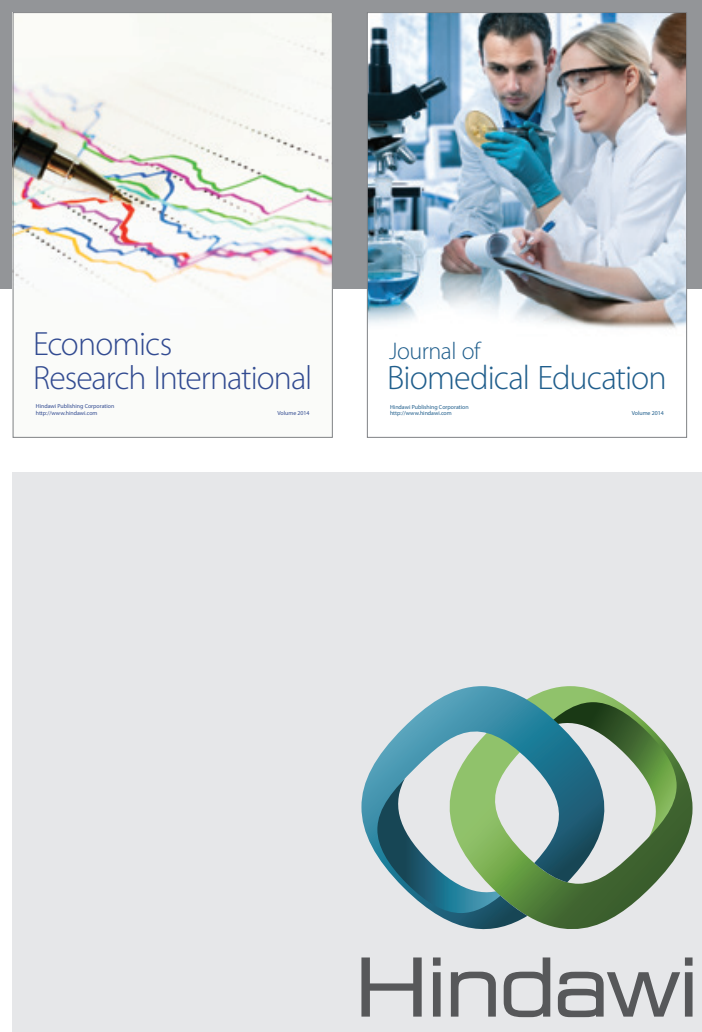

Submit your manuscripts at

http://www.hindawi.com
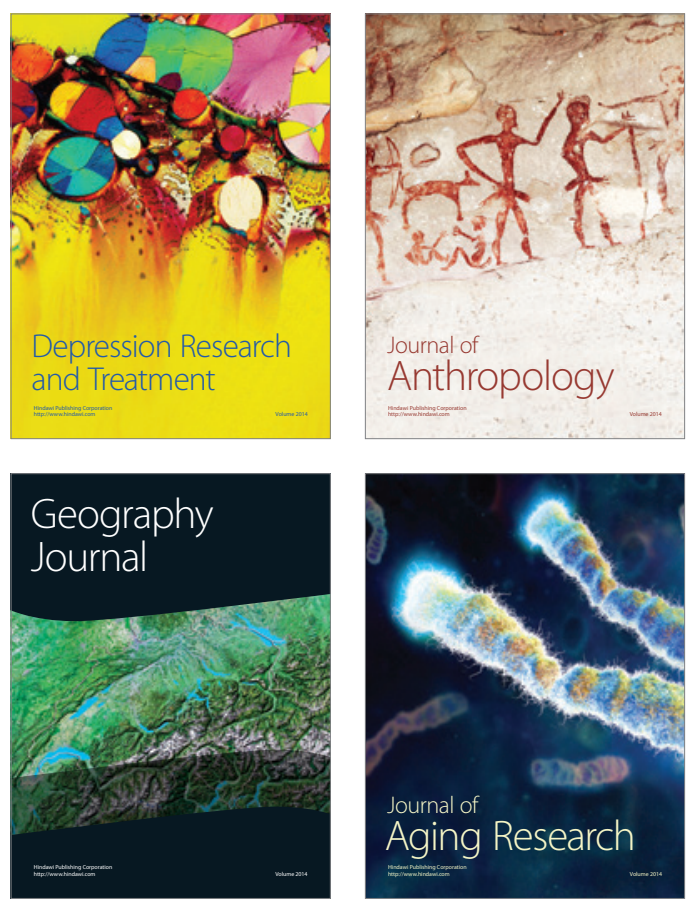
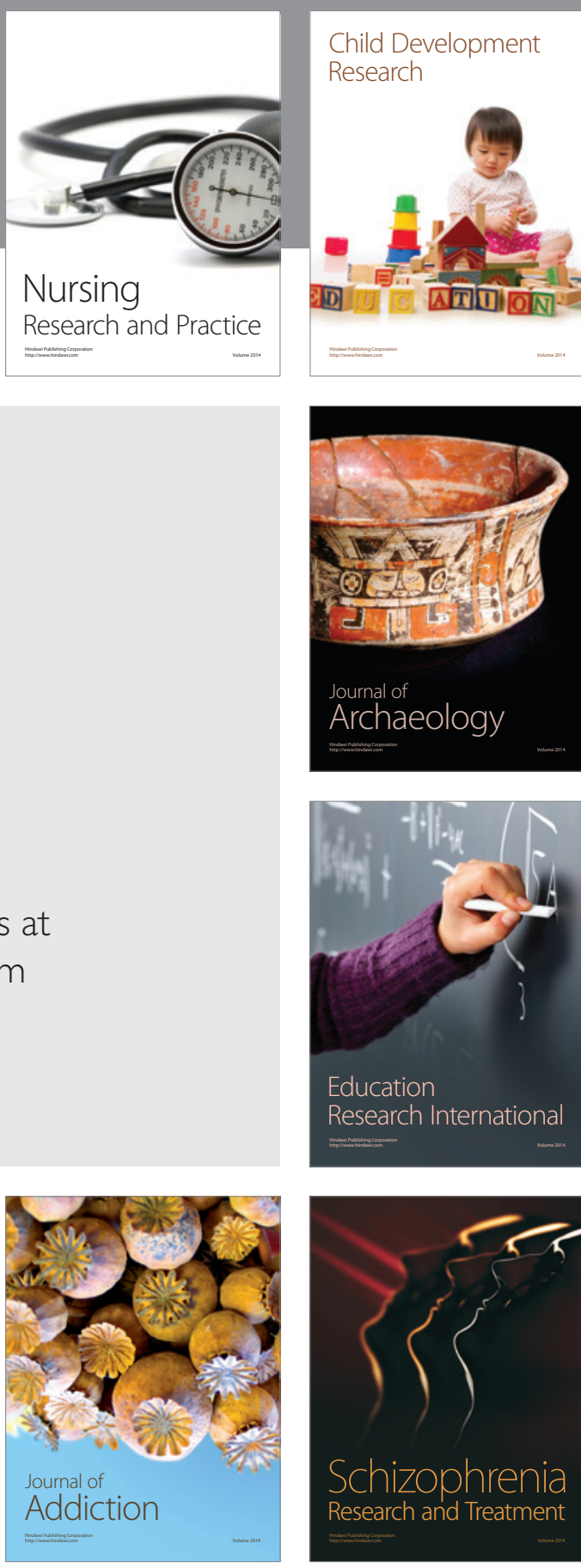

(D)
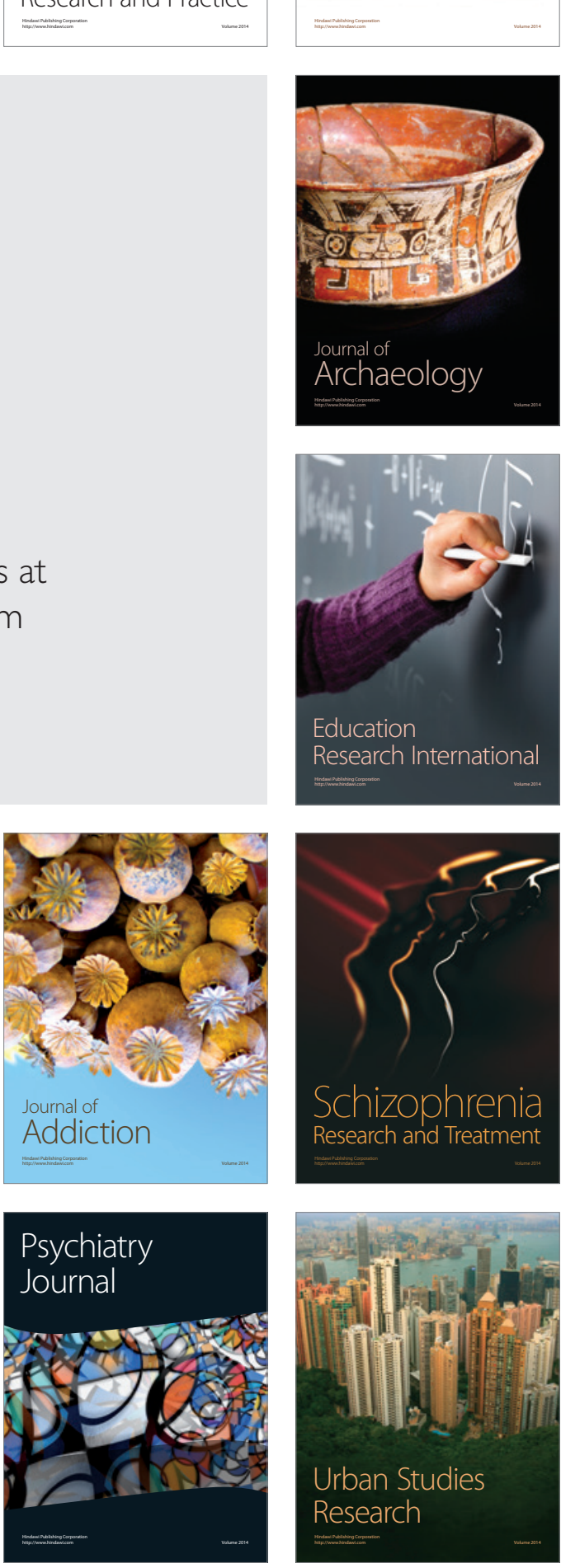